\title{
Expert perspectives on the role of the bus in school travel
}

1 Jessica Van Ristell PhD

Research Associate and Transport Planner, Transport Studies Group, School of Civil and Building Engineering, Loughborough University, Loughborough, UK

2 Marcus Enoch MSc, PhD

Senior Lecturer, Transport Studies Group, School of Civil and Building Engineering, Loughborough University, Loughborough, UK
3. Mohammed Quddus MEng, PhD

Senior Lecturer, Transport Studies Group, School of Civil and Building Engineering, Loughborough University, Loughborough, UK

4 Peter Hardy MSc

Project Director and Transport Planner, JMP Consultants Limited, Birmingham, UK
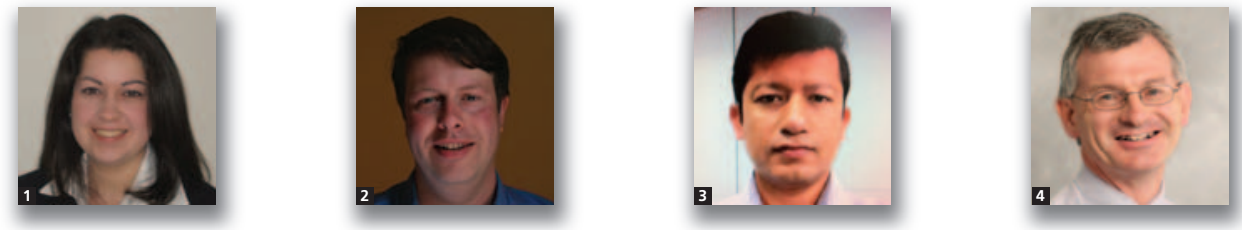

Millions of children travel to and from school each day as part of their daily routine, contributing to increased congestion and traffic on the roads. This paper examines the role of the bus within school travel and reports the views of current professionals in the school travel industry gained from interviews with school travel experts in the UK. The findings suggest that parents, schools, local authorities and bus operators are the key stakeholders, while the children are relatively minor players despite being the main users of the system. The key issues facing the sector concern costs to government and users, institutional and political factors, and social issues around the behaviour of children on buses. The interviewees all see a prominent place for buses in school travel, both now and in the future.

\section{Background and previous work}

Perhaps unsurprisingly, the steady rise in car use around the world in recent years has also applied to education. In Sydney, Australia, $50 \%$ of children travelled to school by car in 2008 2009 (TDC, 2010), in Auckland, New Zealand, 54\% of children travelled to school by car in 2005 (Arta, 2007) and in the USA over $45 \%$ of pupils were driven to school in 2009 (McDonald et al., 2011). As a consequence, much of the existing literature on school travel reflects this increased reliance on cars getting to and from school and the impact this has on, for example, increased congestion on local roads and around the school gate (McDonald, 2008).

One mode of transport that seems somewhat under-researched is the bus. Galliger (2009: p. 44) notes that 'there is a surprising scarcity of research regarding the school bus'. Moreover, the research that does exist tends to focus on four key areas

route optimisation (e.g. Park and Kim, 2008)

safety issues (e.g. Swartz and Reilly, 1995)

- on-board emissions in school buses (e.g. Trenbath et al., 2009)

- emissions generated by school buses (e.g. Gao and Klein, 2010)
In addition, there is a limited body of work on research topics such as the behaviour of children on school buses (Whitehurt and Miller, 1973) and the use of alternative fuels for bus travel to school (Cohen and Diesel, 2005). Wilson et al. (2007) simulated the impacts on cost when a bus service was removed from a community, but, with the exception of three studies (Hine, 2009; Thornthwaite, 2009; Van Ristell, 2011), the existing literature generally steers clear of offering a wider perspective of what the policy issues facing the school bus sector might be.

This paper therefore investigates the role of the bus in school travel. In particular, it determines the key stakeholders involved, the major issues facing the school transport sector and some potential ways forward based on the views of current professionals in the field. The paper details current travel-to-school behaviour in the UK and a more specific view of the school transport policy offered in England, and then provides a methodological outline of the study. The views and opinions of the respondents are then reported before conclusions are offered.

\section{School travel in the UK}

In transport terms, along with other developed countries, the proportion of school children travelling to school by car is 
increasing, from $29 \%$ in $1995-1997$ to $32 \%$ in 2008 (40\% in rural areas) (ONS, 2010), while the corresponding average trip times and annual per person distances over the same period rose from $10 \mathrm{~min}$ to $22 \mathrm{~min}$ and from 193 miles $(310.6 \mathrm{~km})$ to 207 miles $(333 \cdot 1 \mathrm{~km})$ respectively (DfT, 2008; ONS, 2010). Such increases can partly be explained by wider socioeconomic factors, but the policies of successive governments since the 1980s of encouraging parents to choose the schools to which they send their children, in order to stimulate competition among schools and so raise standards (Burgess and Briggs, 2010), have also had an impact: only $43 \%$ of children now attend their nearest school (Van Ristell et al., 2012).

In terms of the bus, most local authorities provide subsidised school travel in some form in order to abide by guidelines set out in the Education Act 1944 (1944). This states that local authorities have a duty to ensure all children (up to the age of 16) can travel to the school closest to their home. However, most local authorities only offer free bus travel if

the student is attending the school closest to their home

- the school is beyond a minimum distance limit away from their home $(2$ miles $(3 \cdot 2 \mathrm{~km})$ if attending primary school and 3 miles $(4 \cdot 8 \mathrm{~km})$ if attending secondary school and sometimes post-16 education establishments).
Schools have been encouraged to adopt so-called school travel plans to improve children's fitness and safety and reduce reliance on car use by introducing measures such as walking and cycling to school schemes (Enoch, 2012).

\section{Method}

A qualitative study based on exploratory in-depth semistructured interviews was conducted to provide greater insight into the issues facing school travel in England. This technique allows elaboration where necessary but control to be maintained (Drever, 1995). Fifteen 'experts' (i.e. individuals with specialised knowledge in a specific field with demonstrated experience and involvement of particular interest to a specific study (Gläser and Laudel, 2004)) were selected to take part based on their profession and expertise in school travel. They included government officers, transport consultants, academics whose research pertains to the transport industry and government advisors; they were initially chosen from the literature review and then by co-nomination (whereby the first interviewees suggested further experts to be included). A purposive sampling strategy was also applied to ensure that the needs of the researcher (high level of expertise and a range of backgrounds) were met (Miles and Huberman, 1994). Table 1 presents details of those interviewed. Interviews were conducted face to face where possible, and via telephone otherwise.

Interviewee Expertise

Transport planners

B Working in the field of sustainable transport promotion, in particular school travel planning and London school travel

J Team leader of the transport department of a county council in central England

K Works within a large council in the school transport planning department in the north of England

$\mathrm{L} \quad$ Works within a large council in the school transport planning department in the south of England

M Works within a large council in the school transport planning department in the north-east of England

$\mathrm{N} \quad$ Works within a large council in the school transport planning department in the north-east of England

O Works within a large council in the school transport planning department in the north-east of England

Consultants

A Experience in public policy and management across transport, planning, education

$\mathrm{F} \quad$ Experience of transport planning and project development working within research, consultancy, central government and local government

G Divisional director of a medium-sized transport consultancy, specialising in passenger transport and accessibility

I Runs a sustainable transport planning consultancy with significant experience in developing travel planning initiatives for schools and workplaces

Academics

C Professor and researcher in bus, coach and rail systems

D Previous school travel advisor; has researched the ability of Quality Bus Partnerships to reduce car use

E Professor and researcher of design processes of cleaner transport and cleaner vehicle technologies, low carbon transport systems and sustainable travel behaviour

Government advisor

$\mathrm{H} \quad$ Representative of bus operators and advisor to government

Table 1. Interviewees and their expertise 
A number of core questions were asked based on the initial literature review findings (or lack thereof) and were designed to address issues relating to

context - definition and characteristics of school travel in general

outcomes - issues related to school travel, focusing on the school bus

process - reasons for school travel plans and current bus provision

a the future prospects of the bus in school travel.

Analysis of the interviews was based on a thematic analysis technique, which is widely used in qualitative studies (Denzin and Lincoln, 2000). During the analysis, the identities of the individuals interviewed were kept anonymous and referred to only by code (e.g. 'interviewee R').

\section{Interviewee results}

\subsection{Stakeholders}

In the view of the interviewees, the key stakeholders involved with school travel by bus are

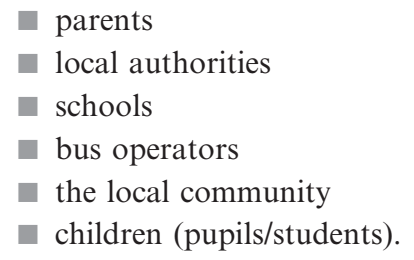

Parents have a profound influence over school travel behaviour, particularly for younger age children, because they decide which school their children will attend and how they travel to and from that school. Interviewee $\mathrm{N}$ (a local authority planner) commented that a major issue he faces is parents' perception that their children 'cannot walk, cannot cycle, cannot go on the bus because of bullying, because it's unsafe, and because there are too many accidents'.

Local authorities also exert influence over school travel. This is both through the provision of subsidised bus travel for eligible pupils (as described earlier) and also through their influence on the routes of bus services operated.

Schools have a say over whether they want buses serving them or not. Some schools can choose to reject bus services and this can have a negative effect on which students attend that school (interviewee L).

Bus operators tender to the local authorities and therefore have the initial say regarding price and service levels. The operators also have a responsibility to the children on their buses to ensure that timetables are realistic.

The local community has little direct influence over school travel, despite being greatly affected by it.

Finally, children appear to have little or no influence over school travel, despite being the 'customers'. This is primarily because parents are the prime decision makers in how their children travel to and from school although, unsurprisingly, this characteristic does become less pronounced for older children.

To summarise, the fact that parents most directly influence school travel behaviour suggests that local authorities need to target their policies and marketing schemes towards parents.

\subsection{Issues and challenges}

The main issues stated by interviewees regarding school travel (particularly by bus) can be considered as economic, political and legal, social, and technological.

\subsubsection{Economic factors}

Economic concerns were dominant among the interviewees when discussing the role of the bus in school travel. These are most evident in the form of 'cost' and are linked to issues relating to

cost to users (i.e. school children and their parents) paying a fare or paying for a subsidised service in the form of a bus pass

cost to local authorities from their transport budget for the contracts to bus operators, specialist vehicles and staff (wages and training)

cost to bus operators (staff costs, fuel costs and vehicle maintenance expenses)

- cost to central government in the form of funding to local authorities.

The interviewees identify the cost of the bus fare to be one of the main influences for children using the bus as a mode of transport to and from school. From a local authority perspective, interviewee A stated that councils 'are spending about a billion pounds a year on home to school travel'. Of this, a significant proportion is spent on travel for children with special education needs and so is difficult to cut because of the range of services required by pupils - anything from access to a standard vehicle (with a vetted driver) to those who need a specialised vehicle with a medically trained escort and driver (interviewee J). Consequently, this 'means less funding is available to extend the current offer of free transport, such as reducing the 3 mile limit to 2 miles or less' (interviewee A). However, even though some local authorities have the budget 
available to do this, the majority of local authorities have kept to the original 3 mile limit. Interviewee B explained that this is because funding to local authorities is never pre-set and has been known to be cut without much warning so a more generous transport policy may be seen as being too much of a risk.

To summarise, the issue of 'who pays for what' was clear in almost all of the interviews as it affects who uses and who does not use the school bus as their main mode of transport to and from school. It is also evident that 'cost' is one of the main influences over whether the bus is a child's main form of transport to and from school.

\subsubsection{Political and legal factors}

As noted earlier, for almost 30 years governments have provided parents with the option to send their child to any school of their choice. This means that "what we have now is an education policy that is encouraging people to travel further and further' (interviewee A) - an opinion shared by many of the interviewees. Moreover, 'the more choice [of school] that is offered, the more difficult it will be to offer services for so many different choices' (interviewee D), with the implication being that meeting travel demand needs is becoming increasingly difficult. Frustratingly for planners, transport and travel do not appear to be a high priority when choosing a child's school when compared with other factors such as school reputation and cost of attendance.

Traditionally, schools have a responsibility to children once inside the school gate, but local authorities are trying to create school travel plans alongside schools to ensure children's safety from home to school throughout the whole journey. This means schools working together with the local authority to design a school travel plan, to monitor it and abide by it.

Parents can also make more of an effort to get their children to school safely without the use of a car: as interviewee N said, 'parents need to acknowledge their responsibility'. To do this, interviewee $O$ suggested they could help by 'walking the children to the bus stop'. Parents can also teach their children how to behave on buses and how to take responsibility for themselves.

For the future, half of the interviewees suggested that the whole approach to school bus policy needs to be looked at again: 'Everyone is just better off starting afresh and looking at the bus situation with a clean slate' (interviewee G).

\subsubsection{Social factors}

Interviewee $\mathbf{J}$ noted many children are happier with the social interaction the bus gives as opposed to the option of walking alone to and from school, and interviewee F stated 'the bus can be a fantastic part of a kid's education'. However, lack of clarity about 'where responsibilities start and finish [where young people are involved] means there are concerns over health and safety' (interviewee G). Developing this, interviewee $\mathrm{C}$ suggested that the bus is more appropriate for children around secondary-school age because of parental concerns regarding safety, particularly bullying. Crucially, these concerns increase the farther children have to travel, thus making sustainable travel options increasingly less attractive to parents who are not choosing to send their offspring to their nearest school.

Such concerns over safety have significantly increased over time. 'Child safety and security are some of the main issues of school travel, and children are now being escorted to a greater degree than in previous generations' (interviewee $\mathrm{C}$ ). Interviewee $\mathbf{J}$ stated that parents need a lot of convincing that the bus is a suitable and safe mode of transport for their children and elaborated that councils should try and work with parents to encourage them to change their perceptions of bus use. According to interviewee $\mathrm{O}$ 'Parents need a deeper understanding of how school transport works'.

Communication between bus operators and schools is also necessary to ensure safe journeys to and from school and good behaviour from children. Schools need to work together with bus operators to provide what interviewee B described as 'a safe journey not only to and from the school gate, but one that extends into the schools gates all the way from home'. Interviewee $\mathrm{K}$ stated that schools should be more involved in promoting bus use 'if they're supporting a service going to their school'.

Schools and local authorities can benefit by working together. Interviewee L noted that schools can help by showing more flexibility in their timetabling, especially given trends where extended school days are becoming more popular for working parents in the form of breakfast clubs, afternoon homework clubs or after-school activities. However, this can be difficult for bus operators. Interviewee $\mathrm{N}$ explained that in rural areas 'the only service serving the school is the school bus service' and if there is only one bus available, the extended school day 'can be a huge problem' (interviewee M).

\subsubsection{Technological factors}

Buses have changed dramatically in the last decade and are continuing to improve. Today, many buses have seat belts, hydraulic mechanisms to allow for easier accessibility, global positioning systems, real-time information and automated payment facilities. However, while this has positives (e.g. CCTV cameras can help reduce bullying and vandalism to buses, and potentially personalised smart card ticketing allows an electronic register of student bus use to be maintained, thus 
reassuring parents), such technology is often expensive. Interviewee J, however, noted that 'The system doesn't have to be complicated. It can be simple. Just have set places to be picked up and dropped off, a reliable service that sticks to its timetable and route, and give children a mobile phone as a backup'. Interviewee $G$ was less enthusiastic saying that 'everything has been tried already' and suggested that there is not much more scope for improvement to school bus services.

\subsection{The future of the bus in school travel}

Overall, among all stakeholders interviewed, there was the feeling that change is needed regarding school bus travel. Interviewee F stated

The bus operators don't like the current system, the council's don't like the current system, the kid's don't like the current system, the parents don't like it, and schools don't like it. There is nothing good about the way we are running bus travel.

Specifically, interviewees noted that the main barriers preventing effective bus use in school travel include the following.

- Cost. This includes the cost of fares and how local authorities try to provide a good-quality service with the limited finance available.

- Attitudes and perceptions. This includes the changing of mind-sets and encouraging parents to allow their children to travel to school by bus is a challenge for most of the stakeholders.

- Services. Limited services including school runs can be restricted by not serving the extended school day and limiting the extra activities children can be involved in.

- Behaviour. Bad behaviour on buses can result in vandalism of the bus or bullying of other children.

Willingness of parents to pay for a service.

In summary, the services offered need to be affordable, but they also need to reflect the cost of the fare and the quality of service received by the users. Attitudes and perceptions are difficult to change but, by targeting each stakeholder in a different and appropriate way, there is a chance that mind-sets can be changed.

\section{Conclusions and implications for policy and practice}

This research sought to determine the role of the bus within school travel and report on the views of current professionals in the school travel industry. Specifically, it focused on the current stakeholders of bus travel, issues regarding school travel, bus use in school travel and the challenges faced by transport planners to ensure pupils have a safe and pleasant journey to and from school.
By identifying the six main stakeholders in school travel (and their level of influence on how children travel to school), policy makers can identify their concerns and focus policy changes on the right groups. The findings suggest that the main stakeholders of school travel are parents, schools, local authorities, communities and bus operators: the students themselves are relatively minor players, despite being the users of the system. Cooperation between stakeholders is vital to encouraging more bus use.

The key issues and challenges facing the sector can be categorised as being related to cost, attitudes and perceptions, limited services, behaviour issues and the willingness of parents to pay for the service. Parental attitudes have strong influences over how children travel. These attitudes have changed over time to become increasingly concerned with safety and quality of services. It was also noted that even though a bus service may be free it still might not be used by children due to other factors (e.g. the bus is seen as an 'unattractive' mode of travel, the risk of bullying, long walks from the bus stop to home/school, among other safety concerns) that, from a parent's view, may outweigh the financial costs incurred by travelling by personal car.

Although the provision of a bus service does pose higher financial consequences to local authorities, there are health, environment and traffic related benefits that can counteract these.

The semi-structured interviews were in-depth and exploratory, allowing flexibility for the interviewees to elaborate where necessary on their own experiences and expertise, and enabled new themes to develop while maintaining control when required. Yet certain limitations, particularly in the range of experiences offered, should also be recognised.

Overall, the interviewees clearly explored the issues surrounding effective school bus travel in England and outlined current barriers. Regarding the future, the research found that the bus still has a prominent place in school travel and will continue to do so in the future as part of the whole spectrum of transport modes.

\section{Acknowledgements}

This research was jointly funded by a grant from the UK Engineering and Physical Sciences Research Council (EPSRC) and Transport Consultants JMP. The authors take full responsibility for the content of the paper and any errors or omissions. The authors would especially like to thank all of those interviewed for their time and opinions.

\section{REFERENCES}

ARTA (Auckland Regional Transport Authority) (2007) Sustainable Transport Plan 2006-16. ARTA, Auckland, New Zealand. 
Burgess S and Briggs A (2010) School assignment, school choice and social mobility. Economic of Education Review 29(4): 639-649.

Cohen JT and Diesel VS (2005) Compressed natural gas for school buses: a cost-effectiveness evaluation of alternative fuels. Energy Policy 33(13): 1709-1722.

Denzin NK and Lincoln YS (2000) Handbook of Qualitative Research. Sage, London, UK.

DfT (Department for Transport) (2008) Transport Statistics Bulletin, National Travel Survey. DfT, London, UK.

Drever E (1995) Using Semi-structured Interviews in Small-scale Research: A Teachers' Guide. Scottish Council for Research in Education, Edinburgh, UK.

Education Act 1944 (1944) Elizabeth II. Chapter 31. Her Majesty's Stationery Office, London, UK.

Enoch MP (2012) Sustainable Transport, Mobility Management and Travel Plans. Ashgate, Farnham, UK.

Galliger C (2009) When the wheels on the bus go round: social interactions on the school bus. Social Psychology of Education 12(1): 43-62.

Gao OH and Klein RA (2010) Environmental equality in participation of the clean air school bus programme: the case of New York state. Transportation Research Part D 15(4): 220-227.

Gläser J and Laudel G (2004) Experteninterviews und Qualitative Inhaltsanalyse. VS Verlag für Sozialwissenschafen, Wiesbaden, Germany (in German).

Hine J (2009) The provision of home to school transport in Northern Ireland. Research in Transportation Economics 25(1): 29-38.

McDonald NC (2008) Household interactions and children's school travel: the effect of parental work patterns on walking and biking to school. Journal of Transport Geography 16(5): 324-331.

McDonald NC, Brown AL, Marchetti LM and Pedroso MS (2011)
U.S. school travel, 2009: an assessment of trends. American Journal of Preventative Medicine 42(2): 146-151.

Miles MB and Huberman AM (1994) Qualitative Data Analysis. Sage, London, UK.

ONS (Office of National Statistics) (2010) Transport: Rise in the Proportion of Primary School Aged Children Travelling to School by Car. ONS, London, UK.

Park K and Kim Y (2008) Analysis of AntNet routing scheme by using queuing model. Computer Communications 31(13): 2951-2958.

Swartz MK and Reilly EA (1995) School bus safety: issues and controversy. Journal of Pediatric Health Care 9(3): 145148.

TDC (Transport Data Centre) (2010) 2008/09 Household Travel Survey Summary Report. New South Wales Transport, Sydney, Australia.

Thornthwaite S (2009) School Transport: Policy and Practice. Landor, London, UK.

Trenbath K, Hannigan MP and Milford JB (2009) Evaluation of retrofit crankcase ventilation controls and diesel oxidation catalysts for reducing air pollution in school buses. Atmospheric Environment 43(37): 5916-5922.

Whitehurt C and Miller E (1973) Behavior modification of aggressive behaviour on a nursery school bus: a case study. Journal of School Psychology 11(2): 123-128.

Wilson EJ, Wilson R and Krizek KJ (2007) The implications of school choice on travel behavior and environmental emissions. Transportation Research Part D: Transport and Environment 12(7): 506-518.

Van Ristell JA (2011) Investigating the Impacts of Policy on School Travel. PhD thesis, Loughborough University, Loughborough, UK.

Van Ristell J, Quddus M, Enoch M, Wang C and Hardy P (2012) Quantifying the transport related impacts of parental school choice in England. Transportation, in press.

\section{WHAT DO YOU THINK?}

To discuss this paper, please email up to 500 words to the editor at journals@ice.org.uk. Your contribution will be forwarded to the author(s) for a reply and, if considered appropriate by the editorial panel, will be published as discussion in a future issue of the journal.

Proceedings journals rely entirely on contributions sent in by civil engineering professionals, academics and students. Papers should be 2000-5000 words long (briefing papers should be 1000-2000 words long), with adequate illustrations and references. You can submit your paper online via www.icevirtuallibrary.com/content/journals, where you will also find detailed author guidelines. 